\title{
Editorial
}

\section{Reforma tributaria: ¿para quién?}

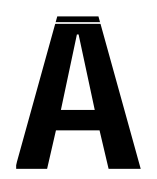

finales de diciembre, el presidente Juan M anuel Santos sancionó la nueva ley que consagra la reforma tributaria, la cual, según él, está orientada a reducir la inequidad distributiva y a bajar el desempleo. Para ello, se excluyeron los parafiscales y se creó la contribución sobre la renta empresarial para la equidad (CREE), que gravará las utilidades de las empresas para financiar una porción de los parafiscales que se eliminar on (ICBF, SENA), como también la contribución a la salud, permitiendo la reducción en los costos laborales, lo que incentivará la creación de nuevos puestos de trabajo y la formalización de los existentes. Por su parte, el ministro de Hacienda manifestó que la nueva ley permitirá disminuir la in equidad, en la medida en que se generará más empleo, y se impondrán menos impuestos a losingresos de los trabajador es y menos IVA a la canasta familiar.

El cumplimiento de los objetivos antes mencionados solo se podrá verificar en los próximos años, y la generación de empleo y el incremento del empleo formal, que, según el gobierno, se alcanzarán con la eliminación de algunos parafiscales, es discutible.

Los empresarios han argumentado que los parafiscales, entre otros factores, han sido los causantes del alto desempleo y de la informalidad laboral. Recordemos que el desempleo en Colombia es del $10 \%$, uno de los más altos de América Latina, y la informalidad es del $60 \%$ de la población económicamente activa, una de las más representativas de la región. Sin embargo, es pertinente preguntar se: ¿incentivará la reducción del costo relativo del trabajo al sector productivo al contratar más trabajadores?

En principio, se puede plantear que si se reduce el costo de un insumo productivo, el efecto puedeser una mayor utilización del mismo; sin embargo, esa decisión va a depender de la rentabilidad que obtengan los productores. Si la demanda efectiva se dinamiza, es decir, si el gasto total tanto del sector privado como del sector público aumenta, habrá más posibilidades de que las personas puedan ser ocupadas acorde con los salarios existentes en la economía. Las firmas, en la medida en que sus ventas aumenten, estarán estimuladas a contratar más mano de obra. Por ello, lo deter minanteno es si se reducen los costos o se les exime del pago de algunos tributos, lo que cuenta es la venta de sus productos.

Los defensores de la decisión gubernamental plantean queal eliminarse los parafiscales, los empresarios tendrán mayores excedentes, pero: ¿quién garantiza que los destinen a contratar 
más trabajadores? El paísya tiene experiencias negativas sobreel particular: la administración de Virgilio Barco Vargas (por medio de la Ley 75 de 1986) eliminó la dobletributación, es decir, el pago de tributación sobre las utilidades delas empresas y dividendos de los accionistas, con el fin de incrementar la inversión y, por ende, el empleo. Los resultados no fueron los esper ados, pues los empresarios atesoraron los recursos, pero no aumentó la inversión. El otro caso se presentó en la administración del presidente Uribe. La reforma laboral sancionada por él (por medio de la Ley 789 de 2002) planteaba que las rigideces laborales eran las causantes del desempleo y que para aumentar el empleo, era pertinente la flexibilización laboral. Para tal fin se amplió la jornada laboral, se redujo el pago de las horas extras y dominicales, entre otras medidas. Los resultados no se expresaron en una reducción del desempleo, sino en mayores ganancias para las empresas, afectando negativamente a los trabajadores, debido a que sus ingresos se redujeron.

El Gobierno también afirma que, al reducirse los costos laborales debido a la eliminación de dos de los parafiscales, los empresarios formalizarán el empleo, no obstante, sobre este punto al igual que sobre la gener ación de empleo, los resultados son inciertos. En primer lugar, el otro parafiscal - el aportea las cajas de compensación familiar - que representa el $4 \%$ dela nómina salarial, se mantiene; en segundo lugar, sigue vigente la contribución del $8.5 \%$ a las pensiones. Estos desembolsos que realizan las empresas pueden constituir se en un obstáculo para la formalización laboral; de allí que prefieran seguir en la informalidad. De igual manera, las empresas informales no se benefician con la reforma si semantienen como han venido funcionando, ya que no pagarán ni par afiscales, ni aportes pensionales, en tanto que si seformalizan, pagarán el $9 \%$ sobre las utilidades hasta el 2015, y, a partir del 2016, el $8 \%$.

Por último, seafirma quela nueva ley contribuirá a la equidad distributiva. Este objetivo es difícil de cumplir, entre otras razones, porquelas rentas de capital, como los dividendos, no pagan impuestos, mientras que los ingresos laborales por medio del impuesto mínimo alter nativo nacional (IM AN), que deter mina la base gravable para el pago de los tributos de losasalariados, a partir de ingresos mensuales superiores a diez millones de pesos, tendrá un gravamen fuerte. Además, los impuestos por ganancias ocasionales correspondientes a sucesiones o ventas de inmuebles, ya no tributarán el $33 \%$, sino el $10 \%$. La propuesta del Gobierno de gravar las pensiones a partir dediez millones mensuales no fue aprobada y se mantuvo la norma existente de gravar las superiores a 26 millones mensuales.

En suma, la creación de nuevos puestos de trabajo y la formalización del empleo dependen de la actitud de los empresarios: hasta quépunto están decididos a contribuir con dicha iniciativa, o si solo les interesa aumentar las ganancias pero no reinvertirlas, acumulando así capital improductivo.

Finalmente, la equidad distributiva está en entredicho, ya que los nuevos impuestos favorecerán las rentas de capital y afectarán negativamente las rentas de trabajo.

LUISE. VALLEJO ZAMUDIO

Editor 